\title{
COMUNICAÇÃO CONJUGAL DURANTE A TRANSIÇÃO PARA PARENTALIDADE NO CONTEXTO DE DEPRESSÃO PÓS-PARTO ${ }^{1}$
}

\author{
Giana Bitencourt Frizzo ${ }^{2}$ \\ Isabela Machado da Silva ${ }^{3}$ \\ Cesar Augusto Piccinini ${ }^{4}$ \\ Rita de Cássia Sobreira Lopes ${ }^{5}$
}

Resumo: O presente estudo investigou a comunicação de casais em que a esposa apresentava indicadores de depressão pós-parto. Participaram 15 casais, em que ambos os cônjuges responderam a entrevistas individuais semiestruturadas. Os dados foram submetidos a uma análise de conteúdo qualitativa, a partir de duas categorias derivadas da literatura: (a) expressão de sentimentos e ideias e (b) resolução de problemas. Identificaram-se dificuldades quanto à expressão de sentimentos e ideias tanto nas esposas como nos maridos. O diálogo sobre os problemas do casal não se mostrou garantia de sua resolução. Brigas, respostas inadequadas aos sentimentos e ideias expressos pelo cônjuge e o desenvolvimento de estratégias comunicacionais que eram percebidas desfavoravelmente pelo outro foram algumas das dificuldades identificadas. Os resultados apoiam estudos que sugerem que a depressão pós-parto pode influenciar a comunicação do casal e a relação conjugal, constituindo esta uma questão relevante para estudos futuros e para o atendimento a essa população.

${ }^{1}$ Agradecemos ao $\mathrm{CNPq}$ pelo apoio financeiro ao projeto de pesquisa e à bolsa de pós-doutorado da primeira autora.

2 Doutora em Psicologia (UFRGS), Professora do Instituto de Psicologia da UFRGS. Endereço para correspondência: Instituto de Psicologia, Universidade Federal do Rio Grande do Sul (UFRGS), Rua Ramiro Barcelos, 2600, Sala 124. CEP 90035-003 - Porto Alegre, RS, Brasil. E-mail: gifrizzo@gmail.com

${ }^{3}$ Psicóloga, mestre e doutoranda pelo PPG - Psicologia UFRGS, bolsista da Coordenação de Aperfeiçoamento de Pessoal de Nível Superior (CAPES-Brasil).

${ }^{4}$ Doutor pela Universidade de Londres (Inglaterra), pesquisador do Conselho Nacional de Desenvolvimento Científico e Tecnológico (CNPq-Brasil) e professor do PPG - Psicologia UFRGS.

${ }^{5}$ Doutora pela Universidade de Londres (Inglaterra), pesquisadora do CNPq-Brasil e professora do PPG - Psicologia UFRGS. 
Palavras-chave: Relacionamento conjugal; depressão pós-parto; comunicação; comunicação conjugal

Marital communication during the transition to parenthood in the context of postpartum depression (Abstract): This study investigated marital communication in couples in which the wives presented indicators of postpartum depression. Participants were 15 couples in which both spouses responded to individual semi-structured interviews. Data were subjected to qualitative content analysis, from two cathegories derived from literature: (a) expression of feelings and ideas and (b) resolution of problems. We have identified difficulties in expressing feelings and ideas by both the wives and the husbands. Dialoguing about couple's problems was not a guarantee of their resolution. Fights, inadequate responses to feelings and ideas expressed by the spouse and the development of communication strategies that were perceived negatively by the other were some of the difficulties identified. Our results support previous studies which suggested that postpartum depression can affect marital communication, and marital relation, making this an issue for future studies and for interventions to attend this population.

Keywords: marital relations, postpartum depression, communication, marital communication

A chegada de um bebé é um período caracterizado por mudanças para cada um dos pais e para o sistema familiar, que passa por uma significativa reestruturação. Segundo a perspectiva da Psicologia do Desenvolvimento, o período de transição para a parentalidade se caracteriza por mudanças na imagem que cada um dos cônjuges tem de si mesmo, do outro e da própria relação (Stern, 1997). As demandas relacionadas ao cuidado de um bebé levam os pais a vivenciarem processos desenvolvimentais específicos, que possibilitarão a realização dessa tarefa e contribuirão para o seu próprio desenvolvimento individual (Benedek, 1970/1983; Colarusso, 1990). No período que antecede ao parto e nos primeiros meses que se seguem a este, a mãe comumente entra num estado especial, denominado "preocupação materna primária" (Winnicott, 1978). Tal condição caracteriza-se por um estado de sensibilidade aumentada, em que a mãe, ao se identificar com o seu bebé, pode responder às necessidades deste, afastando-se temporariamente de seus demais interesses. Nesse contexto, o pai pode funcionar como uma matriz de apoio para a mãe, protegendo-a fisicamente, provendo suas necessidades vitais e diminuindo o impacto das exigências da realidade externa para que ela possa cuidar do bebé (Stern, 1997). 
No entanto, todas essas alterações tendem a influenciar também a relação do casal. Segundo a perspectiva sistêmica (Minuchin, 1982), a transição para parentalidade representa a inclusão de um novo subsistema na família: o parental. O subsistema conjugal deve diferenciar-se para desempenhar a tarefa de socialização da criança, sem perder o apoio mútuo que deveria caracterizá-lo, pois marido e mulher precisam um do outro como um refúgio para as exigências múltiplas da vida.

A partir dessas diferentes perspectivas teóricas, compreende-se que a transição para a parentalidade compreende um momento marcante tanto para o desenvolvimento individual dos pais (Colarusso, 1990; Stern, 1997), como para o desenvolvimento desse sistema familiar (Minuchin, 1982). Alguns autores (Minuchin,1985; Stratton,1988) destacaram que as trocas entre essas abordagens teóricas têm a contribuir para uma compreensão mais abrangente dos fenômenos investigados, que passa a englobar tanto a importância das mútuas relações entre os membros de uma família, como os processos de adaptação e desenvolvimento presentes em cada uma das fases do ciclo vital (Stratton, 1988). Assim, enquanto a Teoria Familiar Sistêmica possibilita compreender a relação do casal durante a transição para a parentalidade, a Psicologia do Desenvolvimento nos permite contextualizar esse momento, destacando as especificidades vivenciadas em função da chegada do bebé, quando o casal necessita construir sua relação com o bebé e adaptar-se e desenvolver-se nesses novos papéis.

Todas as mudanças e reestruturações características desse período fazem com que o mesmo tenda a ser vivenciado como um momento de "stress" pela maior parte dos casais (Bradt, 1995; Carter \& McGoldrick, 1995). Quando se adiciona a esse momento a ocorrência de uma depressão pós-parto, os ajustes necessários tendem a tornar-se ainda mais delicados (Frizzo, Brys, Lopes \& Piccinini, 2010).

A depressão pós-parto é um transtorno que assola de 10 a $37 \%$ das mulheres (Cooper \& Murray, 1995; Cruz, Simões \& Faisal-Cury, 2005). Caracteristicamente, compreende alterações no apetite e sono, crises de choro, desatenção, problemas de concentração, falta de energia e desinteresse por atividades antes consideradas agradáveis (Dunnewold, 1997). Também podem ocorrer ideias de suicídio e sentimentos excessivos de culpa. Os sintomas tendem a ter uma duração razoável de tempo e prejudicam as atividades normais da mulher (O’Hara, 1997).

Diferentes autores têm destacado o impacto que a depressão pós-parto pode exercer nos diferentes relacionamentos familiares, o que engloba tanto a relação mãe-bebé (Brazelton \& Cramer, 1992; Prado et al., 2009; Teti \& Gelfand, 1991) como a relação conjugal (Barnes, 1996). No que se refere ao último caso, Carter, Grigoriadis e Ross (2010) assinalaram que os estudos sobre o tema sugerem uma relação bidirecional entre depressão pós-parto e 
relação conjugal. Dessa forma, ao mesmo tempo em que dificuldades na relação conjugal parecem influenciar o curso e a severidade dos sintomas depressivos, estes parecem vir a contribuir para a existência de dificuldades no relacionamento do casal.

Dimensões variadas do relacionamento conjugal parecem estar envolvidas nesse processo. A depressão pós-parto tem se mostrado associada a menores índices de satisfação conjugal (Mayor, 2004; Moel, Buttner, O'Hara, Stuart, \& Gorman, 2010), assim como a um menor interesse sexual (Moel et al., 2010). Também foram encontradas relações entre o apoio oferecido pelo parceiro e o curso da depressão pós-parto (Bielinsky-Blattman, Lemola, Jaussi, Satadlmayr, \& Grob, 2009). Conforme sugeriram Montgomery, Bailey, Purdon, Snelling e Kauppi (2009), a oferta de apoio emocional e instrumental pelo parceiro contribui para que essas mulheres se sintam mais seguras, melhorando seu bem-estar.

Nesse contexto, a comunicação do casal também parece constituir um aspecto relevante para a compreensão desses processos. Alguns autores (Montgomery et al. 2009; Papp, 2002; Silva \& Piccinini, 2009) destacaram que o fato de a mulher sentir que pode compartilhar suas ideias e sentimentos com o cônjuge tende a ser percebido como uma forma de apoio emocional, contribuindo para a segurança da esposa. Além disso, também foram encontradas associações entre a presença da depressão pós-parto e uma maior ocorrência de conflitos conjugais (Mayor, 2004), de forma que estratégias de comunicação têm sido incluídas como um aspecto a ser trabalhado em modelos voltados ao atendimento desses casais (Carter et al., 2010). Numa revisão teórica realizada por Mayor e Piccinini (2005), os autores apontaram que, quanto mais o casal puder escutar um ao outro, respeitar e aceitar o ponto de vista do outro, mais probabilidades tem de encontrar uma solução para seus conflitos que satisfaça a ambos.

De acordo com Cummings e Davies (1994), mulheres deprimidas podem ter dificuldade em explicar as causas e consequências de suas brigas, o que - assim como sintomas como irritabilidade e desvalia - pode prejudicar a comunicação do casal, especialmente a resolução de problemas. Linares e Campo (2000) corroboraram essa asserção ao descreverem que o evitamento de conflito parece ser bastante comum em casais com a esposa deprimida, exatamente pelo receio de ruptura na relação. Porém, essas estratégias tendem a aumentar a possibilidade de que os problemas não sejam enfrentados de modo eficaz, trazendo potenciais dificuldades para o relacionamento (Walsh, 2002). Além disso, é possível que o marido também esteja deprimido nesse contexto, o que acaba por dificultar ainda mais a existência de uma comunicação adequada e apoiadora entre os cônjuges (Schwengber, Prado, \& Piccinini, 2009; Silva \& Piccinini, 2009). 
Diferentes autores (Olson, 2000; Pittman, 1987; Walsh, 2006) destacaram a importância da comunicação para o funcionamento familiar e conjugal, especialmente diante de situações de crise, como podemos considerar a transição para a parentalidade, especialmente em um contexto de depressão pós-parto. Nesses momentos, justamente quando é considerada mais necessária, a comunicação tende a ser abalada. Uma comunicação direta, clara, específica e honesta, em que as pessoas expressam o que sentem e sentem o que expressam, contribui para as relações familiares (Walsh, 2006). Um autor clássico da terapia familiar, Boszormeny-Nagy (1966), chegou a afirmar que a possibilidade de dialogar com outra pessoa - isso é, responder e compreender o outro, assim como ser compreendido - pode ser considerada como uma forma de crescimento e amadurecimento, pois requer a confirmação de si e do outro, facilitando a individuação de ambos.

Snyder, Cozzi e Mangrum (2002) realizaram uma revisão a respeito do conceito de comunicação na família e sugeriram que a mesma pode ser compreendida a partir de dois componentes principais. O primeiro deles seriam os comportamentos de resolução de conflitos, que envolvem a identificação do problema, o seu esclarecimento, a geração de soluções, a implementação destas e a avaliação geral do processo. O segundo seria a expressão e o reconhecimento de sentimentos. Sardinha, Falcone e Ferreira (2009) também abordaram esses componentes comunicacionais ao descreverem a importância da expressão de sentimentos para a resolução satisfatória de conflitos. No estudo desses autores, ambos os componentes estiveram fortemente associados à satisfação conjugal em casais com no mínimo sete anos de coabitação.

Em suma, a depressão pós-parto tem sido destacada como um transtorno que pode afetar a comunicação do casal tanto no que se refere aos diferentes comportamentos necessários à resolução dos conflitos como no que tange à própria expressão de sentimentos (Cummings, Keller, \& Davies, 2005; Frizzo, 2008; Frizzo, Prado, Linares, \& Piccinini, 2010; Linares \& Campo, 2000; Mayor \& Piccinini, 2005). Assim a comunicação tem se mostrado um aspecto relevante a ser abordado (Carter et al., 2010), podendo contribuir tanto para a relação conjugal em si, como para o curso dos sintomas depressivos. Nesse sentido, o presente estudo visa investigar a comunicação de casais em que as esposas apresentavam indicadores de depressão pós-parto. Com base na literatura revisada, acredita-se que serão identificadas, nesses casais, dificuldades em sua comunicação, especificamente no que se refere a suas habilidades de resolução de problemas e a sua expressão de sentimentos e ideias (Cummings \& Davies, 1994; Linares \& Campo, 2000). 


\section{Método}

\section{Participantes}

Participaram do estudo 15 casais em que a esposa apresentava depressão pós-parto, segundo o Inventário Beck de Depressão (Beck \& Steer, 1993; Cunha, 2001) e uma Entrevista Diagnóstica (GIDEP/NUDIF, 2003a). Os casais selecionados fizeram parte do projeto intitulado "O impacto da psicoterapia para a depressão materna e para a interação pais-bebé: Estudo longitudinal do nascimento ao segundo ano de vida do bebé - PSICDE$M A$ " (Piccinini et al., 2003), que acompanhou em Psicoterapia Breve Pais-bebé 22 famílias com mães com depressão pós-parto ${ }^{6}$. Esses casais foram selecionados a partir do encaminhamento de hospitais públicos de Porto Alegre, de indicações, de anúncios na mídia e de uma unidade básica de saúde. Para fins do presente estudo, foram selecionadas todas as famílias em que o casal coabitava e em que o marido aceitou participar das entrevistas de avaliação inicial. Na Tabela 1, apresentam-se algumas características relevantes acerca dos casais selecionados para este estudo.

\section{Delineamento}

Trata-se de um estudo descritivo que investigou através de entrevistas com os casais a expressão de sentimentos e ideias e a resolução de conflitos, relatadas separadamente pelos maridos e esposas.

\section{Procedimentos}

Inicialmente, preencheu-se a Ficha de Contato Inicial GIDEP/NUDIF (2003b) e foram então agendados dois encontros na Universidade. No primeiro, as esposas e os maridos responderam, individualmente, ao Inventário Beck de Depressão (Beck \& Steer, 1993; Cunha, 2001) e à Entrevista Diagnóstica (GIDEP/NUDIF, 2003a), para confirmar o diagnóstico de depressão da mãe. A seguir, foram realizados a Entrevista de Dados Demográficos (GIDEP/NUDIF, 2003c) e à Entrevista sobre o Relacionamento Conjugal (GIDEP/NUDIF, 2003e). Com o pai, também foi realizada, nessa ocasião, a Entrevista sobre a Experiência da Paternidade (GIDEP/NUDIF, 2003f). No segundo encontro, a esposa respondeu a Entrevista sobre a Experiência da Maternidade (GIDEP/NUDIF, 2003g).

${ }^{6}$ Mais informações sobre o estudo longitudinal - PSICDEMA podem ser encontradas em Frizzo (2008) e Frizzo, Prado, Linares \& Piccinini (2010). 
Tabela 1. Dados Sociodemográficos da Família

\begin{tabular}{|c|c|c|c|c|c|c|c|}
\hline Casal & $\begin{array}{l}\text { Depressãa } \\
\text { mãe }\end{array}$ & $\begin{array}{l}\text { Idade } \\
\text { mãe }\end{array}$ & $\begin{array}{l}\text { Depressão } \\
\text { pai }\end{array}$ & $\begin{array}{l}\text { Idade } \\
\text { pai }\end{array}$ & $\begin{array}{l}\text { Nível socioeco- } \\
\text { nômico da } \\
\text { família }^{a}\end{array}$ & $\begin{array}{l}\text { Sexo } \\
\text { do } \\
\text { bebé }\end{array}$ & $\begin{array}{l}\text { Idade do } \\
\text { bebé em } \\
\text { meses }\end{array}$ \\
\hline 01 & Moderada & 34 & Leve & 29 & Médio Superior & $\mathrm{F}$ & 05 \\
\hline 02 & Moderada & 34 & Mínima & 35 & Médio superior & $\mathrm{F}$ & 07 \\
\hline 03 & Leve & 51 & Mínima & 53 & Baixo & M & 03 \\
\hline 04 & Leve & 42 & Leve & 32 & Superior & $\mathrm{F}$ & 08 \\
\hline 05 & Severa & 24 & Mínima & 35 & Médio inferior & M & 01 \\
\hline 06 & Moderada & 38 & Mínima & 42 & Médio superior & $\mathrm{F}$ & 05 \\
\hline 07 & Moderada & 30 & Leve & 29 & Médio Inferior & $\mathrm{F}$ & 02 \\
\hline 08 & Moderada & 40 & Mínima & 25 & Médio Superior & M & 02 \\
\hline 09 & Severa & 31 & Mínima & 36 & Médio & M & 05 \\
\hline 10 & Severa & 38 & Leve & 44 & Médio Superior & M & 07 \\
\hline 11 & Severa & 32 & Leve & 44 & Superior & M & 07 \\
\hline 12 & Moderada & 38 & Mínima & 29 & Médio Superior & M & 08 \\
\hline 13 & Moderada & 19 & Moderada & 23 & Médio & M & 06 \\
\hline 14 & Leve & 32 & Mínima & 36 & Médio Superior & M & 11 \\
\hline 15 & Leve & 26 & Mínima & 29 & Baixo & $\mathrm{F}$ & 01 \\
\hline
\end{tabular}

O projeto PSICDEMA, do qual este estudo faz parte, foi aprovado por diversos comitês de ética (Hospital de Clínicas de Porto Alegre/ Proc. $\mathrm{n}^{\circ}$ 03-068, 14.02.2003; Hospital Materno Infantil Presidente Vargas/Proc. $\mathrm{n}^{\circ} 05-$ -03, 02.04.2003; UFRGS/Proc. $\left.n^{\circ} 200396,15.05 .2003\right)$, tendo sido considerado adequado e metodologicamente de acordo com a resolução 196/96 do Conselho Nacional de Saúde do Brasil.

\section{Instrumentos}

Ficha de Contato Inicial GIDEP/NUDIF (2003b): buscava investigar os dados sociodemográficos das famílias, bem como avaliar os critérios de inclusão e exclusão do projeto.

Entrevista de Dados Demográficos (GIDEP/NUDIF, 2003c): complementava as informações obtidas na Ficha de Contato Inicial.

Inventário Beck de Depressão (Beck \& Steer, 1993; Cunha, 2001): o BDI é uma escala sintomática de auto-relato, composta por 21 itens, incluindo sintomas e atitudes depressivas, cuja intensidade varia na escala Lickert de 0 a 3 . Esta escala foi desenvolvida a partir de observações clínicas e des- 
crições de sintomas característicos de pacientes depressivos, como um instrumento que pretende avaliar a intensidade da depressão. A consistência interna da versão validada no Brasil do BDI foi de 0,84 e a correlação entre teste e reteste foi de $0,95(\mathrm{p}<0,001)$. Os itens referem-se à tristeza, pessimismo, sensação de fracasso, falta de satisfação, sensação de culpa, sensação de punição, autodepreciação, autoacusações, ideias suicidas, crises de choro, irritabilidade, retração social, indecisão, distorção da imagem corporal, inibição para o trabalho, distúrbio do sono, fadiga, perda de apetite, perda de peso, preocupação somática e diminuição da libido. Esses itens contemplam diferentes alternativas de resposta a respeito de como o sujeito se tem sentido, e que correspondem a diferentes níveis de gravidade da depressão. A soma dos scores dos itens individuais fornece um escore total, que por sua vez constitui um escore dimensional da intensidade da depressão, que pode ser classificado nos seguintes níveis: mínimo (até 11 pontos), leve (de 12 a 19 pontos), moderado (de 20 a 35 pontos) ou grave (acima de 36 pontos).

Entrevista Diagnóstica (GIDEP/NUDIF, 2003a): Esta entrevista foi baseada em Dunnewold (1997) e nos critérios do DSM-IV (APA, 2002), tendo como objetivo investigar os sintomas atuais do pós-parto, a história imediata da mãe e do pai na gestação, a qualidade de seus relacionamentos com o bebé, com sua família e companheiro (a), assim como o histórico médico prévio. As informações obtidas com esta entrevista foram utilizadas para a confirmação dos escores da mãe e do pai no Inventário Beck de Depressão.

Entrevista sobre o Relacionamento Conjugal (GIDEP/NUDIF, 2003d): abordava a qualidade do relacionamento conjugal após o nascimento do bebé, a sexualidade, a comunicação e os sentimentos dos cônjuges em relação ao companheiro.

Entrevista sobre a Experiência da Maternidade (GIDEP/NUDIF, 2003f): entrevista semiestruturada, composta por cinco blocos de questões, buscava investigar os sentimentos da mãe a respeito da maternidade. Durante a entrevista solicita-se à mãe que relate os seus sentimentos e impressões sobre a maternidade desde o nascimento do bebé até o momento da realização da entrevista. Da mesma forma, suas associações eram respeitadas e, caso fosse necessário um maior aprofundamento, a entrevistadora solicitava explicações adicionais à mãe, com o objetivo de esclarecer suas respostas.

Entrevista sobre a Experiência da Paternidade (GIDEP/NUDIF, 2003g) consistiu em uma versão do instrumento utilizado com a mãe, com algumas adaptações para abarcar questões específicas da paternidade.

\section{Análise dos dados}

Este estudo teve como objetivo investigar a comunicação de casais em que as esposas apresentavam indicadores de depressão pós-parto. Os dados 
de todas as entrevistas acima descritas foram submetidos à análise de conteúdo qualitativa (Laville \& Dione, 1999). Na análise de conteúdo, a presença de uma característica importa, de sorte que o novo é sempre considerado, mesmo que alguns elementos apareçam de forma fugaz. Ao desconsiderar isso, corre-se o risco de elementos importantes para compreensão do fenômeno desparecem no processo de análise (Laville \& Dionne, 1999). Além disso, na análise de conteúdo a ênfase está no significado e não na quantificação. Dessa forma, o objetivo é encontrar citações para ilustrar temas específicos, e não atribuir números aos dados (Millward, 2010). Por tudo isso, deve-se dizer que, diferente da teoria fundamentada nos dados, na análise de conteúdo não se busca a saturação teórica (Henwood \& Pidgeon, 2010), de forma que um único exemplo de relato em uma categoria é igualmente importante, dado que busca-se a compreensão do fenômeno estudado. De qualquer forma, para facilitar a descrição dos resultados, a partir da leitura de Hill et al, (2005), optou-se pelas seguintes descrições: a) muitos casos refere-se a mais de metade dos casos, b) boa parte dos casos - envolve em torno de metade dos casos; c) alguns casos - refere-se a 2 a 3 casos; e d) poucos - refere-se a apenas um caso.

Em relação então às categorias de análise, a partir da revisão da literatura acerca dos diferentes componentes comunicacionais (Sardinha et al., 2009; Snyder et al, 2002; Walsh, 2006), estabeleceram-se duas categorias, mutuamente exclusivas:

(a) Expressão de sentimentos e ideias: Nesta categoria, foi investigada a percepção dos participantes quanto à capacidade de os cônjuges expressarem suas ideias e sentimentos. Com esse intuito, consideraram-se apenas os conteúdos surgidos em resposta à pergunta "Vocês conversam sobre o que pensam ou sentem?".

(b) Resolução de problemas: Nesta categoria, considerou-se como os participantes descreveram a forma como o casal lidava com suas dificuldades e seus conflitos. Os conteúdos aqui categorizados surgiram em resposta a perguntas como "Vocês conversam sobre os seus problemas?" e "Como vocês resolvem seus conflitos?”, compreendendo também verbalizações espontâneas dos entrevistados sobre esse tema.

As entrevistas foram analisadas de forma independente pelas duas primeiras autoras deste artigo, ambas psicólogas, sendo uma pós-doutora em Psicologia e terapeuta sistêmica de família, e a outra doutoranda em Psicologia e terapeuta sistêmica de família em formação. As entrevistas foram exaustivamente lidas a fim de identificar as unidades de análise temáticas correspondentes às categorias descritas acima (Laville \& Dione, 1999). Inicialmente foram analisadas todas as entrevistas das esposas e, num segundo momento, as dos maridos. Um terceiro juiz, também coautor do artigo, revisou as categorias analisadas, em um procedimento de auditoria (Morrow, 2005). Eventuais diferenças foram revisadas e discutidas até haver um consenso. 


\section{Resultados}

A seguir, serão apresentados os resultados obtidos de acordo com cada uma das categorias, ilustrando-os com os relatos dos participantes. Serão destacadas tanto as semelhanças como as particularidades nos relatos das esposas e dos maridos.

\section{Expressão de sentimentos e ideias}

Algumas esposas afirmaram que o casal conseguia conversar sobre o que pensa e sente. Todas as demais apresentaram restrições a esse respeito. Entre essas, houve relatos de que a capacidade de conversar sobre pensamentos e ideias dependia do assunto: "A gente procura, na medida do possível, falar tudo. Não fala tudo porque homem nunca entende tudo. Então, não dá pra ter uma conversa... Tem alguns assuntos que eu já me dei conta que ele não evolui. Então, não adianta" (E4) ${ }^{7}$. Para outra esposa, depende do momento: "Às vezes. Mas é assim: Não tem um horário programado. Às vezes dá, às vezes não dá. Às vezes a gente tá conversando chega alguém, ou o bebê chora, não termina aquele assunto e fica assim" (E9). Algumas esposas ressaltaram as dificuldades do marido no que diz respeito a essa questão: "Eu tento conversar com ele, ele não gosta muito, às vezes ele fica bravo com as coisas que eu digo, que eu falo que eu penso, ele não aceita. Aí ele fica invocado, alterado e aí a gente pára de conversar" (E10). Algumas também destacaram as próprias dificuldades a esse respeito, enquanto outras mencionaram tanto as próprias dificuldades como as do marido: "Mais ou menos. Eu acho que agora eu tô mais... Assim, não falo" (E12); "Coisas que eu implico com ele, daqui a pouco ele implica comigo. Quando a gente vê a gente tá discutindo" (E14). Algumas esposas inclusive relacionaram as dificuldades em expressar seus sentimentos e ideias ao momento vivenciado, ou seja, à situação de depressão: "A gente sempre conversou, mas agora tá escassa, horrivel" (E2)

No que se refere aos maridos, apenas um afirmou que o casal consegue conversar sem apresentar nenhuma espécie de restrição, ressaltando, inclusive, que a depressão da esposa não prejudicou o diálogo do casal: "Conversamos, sempre conversamos bastante. Ela infelizmente ficou com esse problema, mas ela fala tudo que ela sente, que ela pensa" (M9). Todos os demais apresentaram algum tipo de restrição em relação a conversar com a esposa. Boa parte dos maridos destacou as dificuldades da esposa em ex-

${ }^{7}$ A letra 'E' significa esposa e o número refere-se ao casal 4, conforme a Tabela 1. A letra ' $M$ ' que aparece em outras falas, refere-se ao marido. 
pressar o que sente ou em responder adequadamente aos conteúdos manifestados pelo marido: "Conseguimos, mas não muito. Só eu. Mais ou menos. Ela não. Tá melhor do que antigamente. Mas ela só fala coisa ruim, digamos assim. Só o que acontece de ruim. Nada de bom. Antigamente, era só de bom. Nada de ruim" (M13). Alguns inclusive mencionaram que a esposa chegou a falar em separação: "É, mas, quando a gente conversa, eu digo o que sinto por ela. Mas ela: 'Tá, então vamos nos separar'. Ela fala bastante... 'Então vamos nos separar, bababá” (M12). Alguns maridos disseram que as conversas entre o casal ocorriam numa frequência que eles consideravam inferior à ideal: "Em alguns momentos, sim, a gente conversa o que a gente tá sentindo, de repente, tem que puxar. A gente, volta e meia, tá buscando falar, mas podia ser mais constante" (M11). Alguns maridos disseram, ainda, que a capacidade de conversar sobre o que pensam e sentem está relacionada ao assunto em questão, sendo que falar sobre o próprio casal pode ser mais difícil do que discutir outros assuntos: "A gente não conversa, a gente não consegue conversar muito. A gente acaba conversando mais por telefone sobre assuntos..., porque ela tem essa coisa da questão da grana, do trabalho" (M4). Deve-se destacar que, na fala de alguns maridos, surge a ideia de que, embora haja conversas e expressão de sentimentos e ideias, o casal não consegue implementar as mudanças desejadas: "A gente conversa várias coisas, só que eu acho que a gente fica muito na conversa. A gente tem consciência da coisa, precisa de um tempo maior para nós, mas a gente acaba não agindo" (M2). Alguns maridos atribuíram a ambos as dificuldades percebidas, sendo que poucos destacaram sua própria responsabilidade: "A gente tá com muita cobrança, eu acho, umas coisas bobas assim que se apegava, era de repente, eu era um tanto mais seco em algumas coisas, de repente" (M11). Poucos maridos também apresentaram uma estratégia para abordar temas delicados usando o humor: "Conversamos assim [mais ou menos], mas falamos. Eu mexo, eu brinco. Ela também” (M8).

\section{Resolução de problemas}

No que se refere à capacidade de conversar sobre os problemas, muitas das esposas responderam afirmativamente a essa pergunta: "Isso é que é o bom dele. Às vezes, não na hora, mas ele vem pra conversar, ele pediu pra conversar! Ele disse que ele ia melhorar, sabia que ele não tinha razão. Então, foi uma coisa, assim: Ele vem colocar as coisas. Eu acho que a gente consegue acertar" (E4). Há também alguns relatos de que o casal tenta conversar, mas briga em seguida: "A gente conversa, mas sempre tem mais conflito no meio do que a própria conversa. A gente não consegue dialogar. A gente fica brigando na realidade. Não é uma conversa: 'Se a gente conseguisse fazer isso e isso, será que não seria melhor?'. Sempre tem uma dis- 
cordância no meio e aquilo ali vira uma discórdia. E daí eu não dou o braço torcer, nem ele" (E8). Outra esposa referiu que consegue conversar, mas precisa de um tempo para isso: "Eu guardo muito as coisas. Se não deu pra conversar hoje... Eu só fui conversar depois, mas não deixei aquilo que eu tinha pra falar pra ele, né? E ele sabia que eu ia falar com ele" (E9). Uma esposa referiu que evita falar: "É que eu sou muito acomodada. Eu vou deixando.... Ai acaba que vai se tornando uma bola de neve, como se transformou. Só que agora eu não quero mais esperar, não tem mais o que esperar, ele já teve tempo suficiente pra mudar, então acho que, se não mudou até agora, não vai mudar mais" (E1). E há algumas esposas que referem que realmente não conversam com o marido: "Não conseguimos conversar" (E15).

No entanto, como a literatura (Walsh, 2002) aponta que conversar sobre os problemas não significa chegar a sua solução, foram analisadas também as falas sobre como o casal resolvia seus conflitos. Foram observadas quatro situações distintas. A primeira diz respeito a algumas esposas que referem não falar mais no assunto que gerou a briga, deixando que o "tempo" resolva a situação: "Ai, às vezes, o tempo se encarrega de resolver. $E$, às vezes, a gente acaba concordando pra não se alongar a discussão." (E11). Em poucos casos, as esposas referiram que também deixam o tempo resolver, mas que o casal "fica de mal" por um tempo: "Ah, eu fico de mal. Quando eu tô muito braba eu fico de mal uns dois dias. Mas normal. A gente se beija igual, quando ele chega, a gente dá oi, a gente conversa normal, mas eu fico braba com ele. Sabe que a gente não tem muito contato. Só quando chega e quando sai. Mas eu fico braba, assim, dai depois vou indo, ainda penso: 'Ah, meu Deus!', e dai passa!' (E9). Em alguns casos, as esposas referiram que as brigas são solucionadas quando o marido cede e reconhece os erros: "Brigando, discutindo, geralmente ele fica alterado, não sabe falar baixo, ele fala muito alto, a gente grita bastante e briga, às vezes a gente vai dormir bravo. E ficam os dois de mal. As vezes ele me liga... Esses tempos a última briga que a gente teve eu briguei com ele, nós brigamos, eu fiquei de mal com ele, eu não me lembro o que é que foi a briga. Ai eu fui dormir braba com ele, fiquei muito magoada com ele, não falei mais com ele, aí, no outro dia, ele tentava falar comigo e eu não falava mais com ele, não falava com ninguém, fiquei... Me isolei. Ai ele me ligou chorando que não conseguia ficar de mal comigo, pediu desculpa" (E10). Embora o diálogo seja mencionado em boa parte dos relatos, em nenhum deles, é apontado como a primeira forma de resolver os conflitos: "As vezes, a gente nem resolve, às vezes, a gente briga, fica um tempo sem se falar e depois a gente vai voltando aos pouquinhos. Mas, às vezes, a gente conversa e a gente acaba se entendendo, resolvendo, no caso" (E13). 
Em relação aos maridos, foram destacadas quatro situações acerca do conversar sobre problemas em geral. Assim como destacado entre as esposas, em muitos casos, os maridos afirmaram que o casal conversa sobre os problemas. Dos que relataram que conseguem conversar, alguns disseram que fazem isso normalmente: " $E$, a gente tem conseguido conversar, é a mesma coisa assim que a gente não concorda um com outro em tudo, tem certas coisas que a gente discorda, tanto ela de mim quanto eu dela, então a gente é assim, mas a gente chega a um certo ponto" (M3). Alguns outros relataram que a conversa termina em discussão: "A gente conversa, mas, às vezes, um dos dois escolhe o momento errado de resolver. Eu acho que é ela, mas eu dou direito ao contraponto" (M4). Poucos referiram que precisam de um tempo para poder conversar: "A gente sempre acabava conseguindo conversar de uma forma ou outra pra poder manter a relação, sempre conseguiu. Às vezes, passava alguns dias. Ela é mais de resolver na hora, eu sou um pouquinho mais rancoroso... Me deixa um pouco, pra ganhar um pouco mais tempo, chateado até me acalmar ou até achar que, até o momento meu... Às vezes, conversava com mais tempo. Ela tem uma confusão e quer resolver, mas eu acho que tá certo também, mas então é isso, se eu tenho um relacionamento com ela há nove anos é porque a gente teve um equilíbrio” (M11). Poucos maridos também referiram que desistiram de conversar com a esposa: "Eu tento conversar sobre o nosso relacionamento. Tento conversar uma vez, duas vezes. Na terceira, já não converso mais. Antigamente era umas dez vezes que eu tentava." (M13).

Já quando perguntados sobre como resolvem seus conflitos, os maridos apresentaram respostas muito diversificadas. Muitos maridos relataram que evitam tocar no assunto que gerou o conflito: "A gente briga assim, discute, dai a gente pega... Daí fica um... Cada um no seu canto, quieto. Daí passa o tempo e a gente volta ao normal" (M15). Alguns relataram dialogar sobre o conflito em busca de uma solução: "Dando a melhor solução possivel, de comum acordo de ambas as partes" (M9). Os demais relataram que tentam usar o humor para desarmar a esposa: "Fazer ela rir. É a forma que eu encontro pra resolver. Eu não sei outra forma. Falar besteira. Fazer rir pra descontrair" (M8). Poucos disseram tentar mudar de assunto "Ah, eu procuro ficar... às vezes, eu me imponho, ou, às vezes, de repente, quando tá num patamar que pode causar uma desavença maior, ai eu procuro mudar de assunto, ou 'ah, tenho que fazer tal coisa', tento desvirtuar" (M7). Poucos também referiram ficar de mal e só então tentar conversar "Cada um ficava do seu lado, se discutia e depois chegava um momento em que tinha de se falar, isso é, essa válvula aí, esse mecanismo que fazia a coisa não se tornar pior, a gente fazia, eu sempre fui mais rancoroso assim, eu precisava de um pouco mais de tempo, até podia falar, porque eu sinto uma dificulda- 
de assim, essa dureza, então minimizar o tempo, tu entendeu? De mal-estar, se os dois ficavam mal, eu ia mal pro serviço e ela ia mal pro serviço, daqui a pouco um ligava pro serviço e pedia desculpas, aí a gente já amenizava e depois a gente conversava. Então, a gente tinha mecanismos, assim quando o tempo passava, de equilibrar a coisa" (M11). Outros poucos maridos relataram que tentavam conversar, mas que a esposa não aceitava: "Eu tento conversar, só que em cabeça fechada não entra nada. Tento conversar, mas ela não conversa” (M13).

\section{Discussão}

Os resultados revelaram dificuldades nesses casais no que se refere à expressão de sentimentos e ideias tanto por parte das esposas como dos maridos. As esposas relataram tanto dificuldades de se expressar como de se sentirem compreendidas. Nos maridos, houve queixas de a mulher não se abrir e de não responder adequadamente aos sentimentos expostos por eles. A expressão de sentimentos e ideias é amplamente admitida na literatura como um fator importante para a satisfação conjugal, podendo ser vista como uma forma de apoio emocional disponibilizada pelo parceiro, especialmente no contexto da depressão pós-parto (Montgomery et al., 2009). Além disso, quando o casal consegue compartilhar seus sentimentos, desejos, necessidades de forma assertiva, ficam facilitados os processos de resolução de problemas, uma vez que se esclarece o que é esperado de cada um (Sardinha et al., 2009). Não surpreende, portanto, que os casais do presente estudo que relataram não conseguir expressar adequadamente seus sentimentos e ideias apresentassem também dificuldades na resolução de problemas.

Os relatos dos participantes também demonstraram que ao menos algumas das dificuldades vivenciadas tendem a ser identificadas por eles. No entanto, seus relatos sugerem que eles não sabem como ir além dessa identificação, para a elaboração ou implementação de soluções adequadas (Snyder et al, 2002; Walsh, 2002). No estudo de Linares e Campo (2000) com mulheres deprimidas, o evitamento de conflito apareceu como uma forma de evitar a ruptura da relação, o que não foi corroborado no presente estudo. A separação do casal foi aqui apontada, algumas vezes, como única possibilidade de solução para as dificuldades vivenciadas, o que pode estar relacionado com a dificuldade na habilidade de resolução de problemas presente na depressão (Cummings \& Davies, 1994; Teti \& Gelfand, 1991). Demonstra-se, portanto, um déficit na capacidade de responder adequadamente tanto aos sentimentos vivenciados, como aos sentimentos expostos pelo cônjuge. Isso se aproxima ao já observado por outros autores (Brazelton \& Cramer, 
1992), no que se refere à própria relação mãe-bebé no contexto da depressão pós-parto, em que as mães apresentariam dificuldades em responder de forma adequada às necessidades e aos sinais do bebé.

Observou-se, ainda, no presente estudo que o conteúdo a ser comunicado também parece influenciar a efetividade do processo comunicacional (Watzlawick, Beavin \& Jackson, 1975). Houve relatos de que o casal conseguia expressar mais facilmente sentimentos e ideias relacionados ao cotidiano do que aqueles referentes à própria relação conjugal. Além disso, identificou-se uma tendência, por parte das esposas, à maior expressão das dificuldades e insatisfações, sendo que a expressão dos demais sentimentos e ideias parece ficar em segundo plano. É possível relacionar essa tendência às próprias características do humor deprimido, em que tende a haver um maior destaque a essas questões.

No que se refere à resolução de problemas, embora os participantes do presente estudo tenham afirmado conversar sobre os mesmos, foi possível perceber que essa tende a não ser a principal estratégia de resolução de conflitos, pois essas conversas podem se transformar em brigas ou não serem concluídas de forma satisfatória pelo casal. Dessa forma, evidencia-se que o diálogo mencionado por esses casais não garante a resolução efetiva dos conflitos. Conforme pontuado por Snyder et al. (2002), a resolução de conflitos envolve uma série de fases, que englobam a identificação do problema, o seu esclarecimento, a geração de soluções, a implementação destas e a avaliação geral do processo. Assim, parece que, mesmo quando conseguem identificar e expressar suas dificuldades e insatisfações, podem ser encontrados problemas nas demais fases desse processo, tais como a falta de uma real compreensão dessas dificuldades e insatisfações ou, ainda, respostas inadequadas às mesmas.

Outra possibilidade a ser considerada ao se tentar compreender por que os diálogos nesses casais tendem a se transformar em brigas ou a não levarem a resoluções satisfatórias refere-se ao que Fincham (2009) chamou de "reciprocidade negativa". De acordo com esse autor, casais em dificuldade tenderiam a realizar, com mais frequência, afirmações consideradas negativas e a também apresentar comportamentos tidos como negativos, tais como desqualificar o outro e focar-se em queixas e lamentações. A apresentação desses comportamentos por parte de um dos cônjuges contribuiria para que o outro respondesse de forma semelhante, o que caracteriza a reciprocidade. Como mencionado anteriormente, os dados do presente estudo parecem corroborar a ideia de que, nesses casais, há uma maior expressão das insatisfações e dificuldades, o que poderia favorecer esse ciclo. Além disso, Fincham (2009) chama a atenção para a importância dos comportamentos 
não verbais - postura, olhares e tom de voz - para a forma como são manejados os conflitos. Essa questão não foi investigada no presente estudo, mas constitui um elemento relevante a ser abordado em estudos futuros, especialmente considerando-se o contexto de transição para a parentalidade, em que a comunicação não-verbal se mostra tão importante, uma vez que constitui o principal canal de comunicação entre a mãe e o seu bebé (Brazelton \& Cramer, 1992).

Além disso, com base nos resultados do presente estudo, tem-se a impressão de que as estratégias desenvolvidas para a resolução dos problemas vivenciados são elaboradas individualmente e não necessariamente pelo casal, sendo assim, constata-se que as estratégias propostas por um dos cônjuges nem sempre são percebidas como satisfatórias pelo outro. Segundo Papp (2002), homens e mulheres lidam de forma diferente com a depressão. De acordo com a autora, quando as mulheres estão deprimidas, os homens tendem a dar sugestões práticas sobre como resolver o problema, indicando estratégias de ação, diferentemente das mulheres, que gostariam de poder conversar sobre seus sentimentos. Em relação especificamente ao uso do humor como forma de amenizar os sintomas depressivos - estratégia usada por poucos maridos deste estudo e que foi mal-interpretada por suas esposas - embora Walsh (2006) tenha ressaltado a importância do humor para lidar com situações estressantes, é necessário que o mesmo seja utilizado dentro de um contexto empático para que efetivamente cumpra essa função. O humor pode não ser uma boa estratégia se o cônjuge entendê-lo como uma provocação ou desvalorização de seu sofrimento e não como uma forma de cuidado. Em um dos casos de psicoterapia pais-bebé no contexto da depressão pós-parto, analisados pormenorizadamente por Frizzo (2008), o uso do humor por parte dos maridos foi bastante mal-interpretado pela esposa deprimida, no início do tratamento, pois esta referia que o marido não a compreendia.

No entanto, ao analisarmos os resultados do presente estudo devemos considerar que esses casais se encontravam em um momento muito específico do seu ciclo vital. O nascimento de um bebé causa importantes "revoluções" nas famílias, uma vez que reativa as próprias posições infantis, angústias e depressões primárias (Golse, 2003). Para que possam compreender as necessidades do bebé, os pais se identificam com ele (Winnicott, 1978), de forma que prevalece uma forma de relacionamento em que estão presentes suas próprias partes infantis. Assim, é possível que o funcionamento específico dos subsistemas familiares nesse período possa dificultar o diálogo do casal, entendido como um processo posterior no desenvolvimento, quando o ser humano já pressupõe a existência de si e do outro, ou seja, o diálogo como uma possibilidade de crescimento, amadurecimento e individuação (Boszormeny-Nagy, 1966). Além disso, deve-se ressaltar que, nesse período, 
a conjugalidade deixa de ser o relacionamento central para as famílias, em virtude de todas as demais reestruturações que necessitam ser realizadas (Hackel \& Ruble, 1992).

Ainda assim é importante que o casal consiga manter o apoio mútuo que deveria caracterizar o subsistema conjugal, pois marido e mulher precisam um do outro como um refúgio para as exigências múltiplas da vida (Minuchin, 1982), especialmente em um contexto de depressão pós-parto em que a mãe vivencia uma necessidade adicional de ser cuidada e em que o pai pode se sentir sobrecarregado por suas responsabilidades (Montgomery et al., 2009; Pittman, 1987). No estudo de Frizzo (2008), foi evidenciado o quanto o equilíbrio no apoio entre os cônjuges tende a ser retomado quando os sintomas depressivos são amenizados, após uma Psicoterapia Breve Pais-bebé.

\section{Considerações Finais}

As evidências reveladas no presente estudo corroboram a literatura ao sugerirem a presença de dificuldades na comunicação do casal, especificamente no contexto de depressão pós-parto. Identificaram-se dificuldades em diferentes componentes comunicacionais e nas diversas fases que compreendem o processo de resolução de conflitos. Dessa forma, casais que, embora conseguissem identificar e expressar suas dificuldades, por vezes, não seguiam adiante no processo de solucioná-las. Respostas inadequadas à expressão dos sentimentos do outro ou o desenvolvimento de estratégias por parte de um dos cônjuges, que eram percebidas desfavoravelmente pelo outro foram algumas das dificuldades identificadas. Destaca-se a necessidade de mais estudos que ampliem a compreensão da comunicação conjugal nesse contexto, especialmente considerando sua importância para a satisfação conjugal e os efeitos que possíveis conflitos entre os pais podem exercer nos filhos (Fincham \& Hall, 2005). Outra sugestão seria que novos estudos investigassem que aspectos contribuem para a satisfação conjugal durante a transição para parentalidade, além da comparação de famílias em que a mãe apresenta ou não depressão pós-parto, a fím de construir um modelo teórico acerca dos factores que contribuem para uma comunicação conjugal eficaz nesta fase do ciclo de vida da família.

Entre os méritos deste estudo, encontram-se a utilização de uma entrevista que contém questões sobre os diferentes componentes do processo comunicacional, o que permitiu identificar diferentes estágios da resolução de conflitos. Além disso, a análise qualitativa constitui um recurso pouco explorado na investigação desse tema pela literatura e se mostrou relevante na identificação de possíveis áreas às quais os profissionais devem estar 
atentos ao atenderem esses casais, o que se mostra útil uma vez que a comunicação vem sendo destacada como uma dimensão a ser trabalhada nesse contexto (Carter et al., 2010).

No entanto, uma limitação desse estudo refere-se à não investigação da estrutura da relação conjugal anterior ao nascimento do bebé, a qual possui grande influência no ajustamento após o nascimento do filho (Menezes \& Lopes, 2007). Podemos pensar que essa estrutura prévia do casal também influenciaria sua resposta a outras dificuldades que podem surgir em sua vida, como uma situação de depressão pós-parto (Frizzo, 2008; Frizzo et al, 2010; Prado et al, 2009; Schwengber et al, 2009; Silva \& Piccinini, 2009), contexto este que se sobrepõe a uma crise normativa do ciclo de vida familiar (Carter \& McGoldrick, 1995), aumentando a pressão sobre o sistema conjugal. Dessa forma, estudos que incluam essas questões tendem a contribuir para ampliar a compreensão sobre a comunicação conjugal no contexto de depressão pós-parto.

Intervenções com famílias após o nascimento do bebê devem levar em conta a especificidade desse momento no ciclo vital, além de focar na qualidade da comunicação do casal, que pode estar associada a uma eventual depressão da mãe, que muitas vezes é subdiagnosticada nos serviços de saúde e que pode impactar tanto o subsistema conjugal como o parental. Em casais em que já há diagnóstico de depressão pós-parto da mãe, seria importante que a psicoterapia pudesse contemplar além de aspectos específicos da relação mãe-bebé, os componentes comunicacionais tanto de expressão de sentimentos e ideias como de resolução de problemas, que podem estar comprometidos em alguns casos, contribuindo para o surgimento de dificuldades no relacionamento desses casais.

\section{Referências}

Boszormeny-Nagy, I. (1966). From family therapy to a psychology of relationships: fictions of the individual and fictions of the family. Comprehensive Psychology, 7, 408-423.

Barnes, D. L. (2010). Postpartum depression: Its impact on couples and marital satisfaction. Journal of Systemic Therapies, 25(3), 25-42.

Benedek, T. (1983). La familia como campo psicológico. In E. J. Antony, \& T. Benedek, Parentalidad (pp. 119-145). Buenos Aires: Amorrortu. Original published in 1970.

Bielinski-Blattmann, D., Lemola, S., Jaussi, C., Stadlmayr, W., \& Grob, A. (2009). Postpartum depressive symptoms in the first 17 months after childbirth: The impact of an emotionally supportive partnership. International Journal of Public Health, 54, 333-339. 
Bradt, J. O. (1995). Tornando-se pais: Famílias com filhos pequenos. In B. Carter \& M. McGoldrick (Eds.), As mudanças no ciclo de vida familiar - uma estrutura para a terapia familiar (pp. 206-222). Porto Alegre: Artes Médicas.

Brazelton, T. B., \& Cramer, B. G. (1992). As primeiras relações. São Paulo: Martins Fontes.

Carter, B., \& McGoldrick, M. (1995). As mudanças no ciclo de vida familiar - uma estrutura para a terapia familiar. In B. Carter \& M. McGoldrick (Eds.), As mudanças no ciclo de vida familiar - uma estrutura para a terapia familiar (pp. 7-29). Porto Alegre: Artmed.

Carter, W., Grigoriadis, S., \& Ross, L. E. (2010). Relationship distress and depression in postpartum women: Literature review and introduction of a conjoint interpersonal psychotherapy intervention. Archives of Women's Mental Health, 13, 279-284.

Colarusso, C. A. (1990). The third Individuation: The effect of biological parenthood on separation-individuation processes in adulthood. Psychoanalytic Study of the Child, 45, 179-194.

Cooper, P. J., \& Murray, L. (1995). Course and recurrence of postnatal depression: evidence for the specificity of the diagnostic concept. British Journal of Psychiatry, 166, 191-195.

Cruz, E. B. S, Simões, G. L., \& Faisal-Cury, A. (2005). Rastreamento da depressão pós-parto em mulheres atendidas pelo Programa de Saúde da Família. Revista Brasileira de Ginecologia e Obstetrícia, 27, 181-188.

Cummings, M. E., \& Davies, P. T. (1994). Maternal depression and child development. Journal of Child Psychology and Psychiatry, 35, 73-112.

Cummings, M. E., Keller, P. S., \& Davies, P. T. (2005). Towards a family process model of maternal and paternal depressive symptoms: exploring multiple relations with child and family functioning. Journal of Child Psychology and Psychiatry, 46, 479-489.

Dunnewold, A. L. (1997). Evaluation and treatment of postpartum emotional disorders. Sarasota: Professional Resource Press.

Fincham, F. D. (2009). Marital conflict. In H. T. Reis \& S. Sprecher (Eds.), Encyclopedia of Human Relationships (Vol 1, pp. 298-303). Thousand Oaks: Sage.

Fincham, F.D., \& Hall, J.H. (2005). Parenting and the marital relationship. In T. Luster \& L. Okagaki (Eds.), Parenting: An ecological perspective (pp. 205-234). Hillsdale: Erlbaum.

Frizzo, G. B. (2008). Contribuições da psicoterapia breve pais-bebê para a conjugalidade e para a parentalidade em contexto de depressão pós-parto. Unpublished doctoral dissertation, Universidade Federal do Rio Grande do Sul, Porto Alegre, Rio Grande do Sul, Brasil.

Frizzo, G. B., Brys, I., Lopes, R. C. S., \& Piccinini, C. A. (2010). Conjugalidade em contexto de depressão da esposa no final do primeiro ano de vida do bebê. Aletheia, 31(1), 66-81.

Frizzo, G. B., Prado, L. C., Linares, J. L., \& Piccinini, C. A. (2010). Depressão pós-parto: Evidências a partir de dois casos clínicos. Psicologia: Reflexão e Crítica, 23(1), 46-55. 
GIDEP/NUDIF. (2003a). Entrevista Diagnóstica. Unpublished instrument. Instituto de Psicologia - Universidade Federal do Rio Grande do Sul, Porto Alegre, Rio Grande do Sul, Brasil.

GIDEP/NUDIF. (2003b). Ficha de Contato Inicial. Unpublished instrument. Instituto de Psicologia - Universidade Federal do Rio Grande do Sul, Porto Alegre, Rio Grande do Sul, Brasil.

GIDEP/NUDIF. (2003c). Entrevista de Dados Demográficos. Unpublished instrument. Instituto de Psicologia - Universidade Federal do Rio Grande do Sul, Porto Alegre, Rio Grande do Sul, Brasil.

GIDEP/NUDIF. (2003d). Entrevista sobre Relacionamento Conjugal. (Unpublished instrument. Instituto de Psicologia - Universidade Federal do Rio Grande do Sul, Porto Alegre, Rio Grande do Sul, Brasil.

GIDEP/NUDIF. (2003e). Entrevista sobre Experiência da Paternidade. Unpublished instrument. Instituto de Psicologia - Universidade Federal do Rio Grande do Sul, Porto Alegre, Rio Grande do Sul, Brasil.

GIDEP/NUDIF. (2003f). Entrevista sobre Experiência da Maternidade. Unpublished instrument. Instituto de Psicologia - Universidade Federal do Rio Grande do Sul, Porto Alegre, Rio Grande do Sul, Brasil.

Golse, B. (2002). O que temos aprendido com os bebês. In L. Corrêa Filho, M. E. G., Corrêa, \& P. S. França (Eds.), Novos olhares sobre a gestação e a criança de 0 a 3 anos - Saúde perinatal, educação e desenvolvimento do bebê (pp. 116-134) Brasília: L.G.E. Editora Ltda.

Hackel, L. S., \& Ruble, D. N. (1992). Changes in the marital relationship after the baby is born: predicting the impact of expectancy disconfirmation. Journal of Personality and Social Psychology, 9, 944-957.

Henwood, K., \& Pidgeon, N. (2010). Teoria Fudamentada. In G.M. Breakwell, S. Hammond, C. Fife-Schaw \& J.A. Smith, Métodos de pesquisa em psicologia (pp. 340-361). Porto Alegre: Artmed.

Hill, C. E., Knox, S., Thompson, B. J., Williamns, E. N., Hess, S. A., \& Ladany, N. (2005). Consensual Qualitative Research: An Update. Journal of Counseling Psychology, 52(2), 1-27.

Laville, C., \& Dione, J. (1999). A construção do saber: manual de metodologia da pesquisa em ciências humanas. Porto Alegre: Artmed.

Linares, J. L., \& Campo, C. (2000). Tras la honorable fachada: los transtornos depresivos desde una perspectiva relacional. Barcelona: Paidós.

Mayor, I. M. B. (2004). A qualidade do relacionamento conjugal no contexto da depressão materna. Unpublished master's thesis. Universidade Federal do Rio Grande do Sul, Porto Alegre, Rio Grande do Sul, Brasil.

Millward, L.J. (2010). Grupos Focais. In G.M. Breakwell, S. Hammond, C. Fife-Schaw \& J.A. Smith, Métodos de pesquisa em psicologia (pp. 278-300). Porto Alegre: Artmed.

Moel, J. E., Buttner, M. M., O’Hara, M. W., Stuart, S., \& Gorman, L. (2010). Sexual function in the postpartum period: Effects of maternal depression and interpersonal psychotherapy treatment. Archives of Women's Mental Health, 13, 495-504 . 
Minuchin, P. (1985). Families and individual development: Provocations from the field of family therapy. Child Development, 56, 289-302.

Minuchin, S. (1982). Famílias: Funcionamento e tratamento. Porto Alegre: Artes Médicas.

Montgomery, P., Bailey, P., Purdon, S. J., Snelling, S. J., \& Kauppi, C. (2009). Women with postpartum depression: "My husband" stories. BMC Nursing, $8(8)$ [Electronic version]. Retrieved in June, 06, from http://www.biomed central.com/1472-6955/8/8.

Morrow, S. L. (2005) Quality and trustworthiness in qualitative research in counseling psychology. Journal of Counseling Psychology, 52(2), 250-260.

O'Hara, M. W. (1997). The nature of postpartum depressive disorders. In L. Murray \& P. J. Cooper. Postpartum depression and child development (pp. 3-34). New York: The Guilford Press.

Olson, D. H. (2000). Circumplex model of marital and family systems. Journal of Family Therapy, 22, 144-167.

Papp, P. (2002). As diferenças de gênero e a depressão: a depressão dele e a depressão dela. In Casais em perigo: Novas diretrizes para terapeutas (pp. 145-166). Porto Alegre, Artmed.

Prado, L. C., Gomes, A. G., Silva, M. R., Frizzo, G. B., Alfaya, C. A. S., Schwengber, D. D. S., Lopes, R. C. S. \& Piccinini, C. A. (2009) Psicoterapia breve pais-bebê: Revisando a literatura. Revista de Psiquiatria do Rio Grande do Sul, 31, $1-13$.

Piccinini, C., Prado, L., Lopes, R., Schwengber, D., Alfaya, C., Frizzo, G., Mayor, I., \& Silva, M. (2003). O impacto da psicoterapia para a depressão materna e para a interação pais-bebê: Estudo longitudinal do nascimento ao segundo ano de vida do bebê. (Unpublished study). Instituto de Psicologia - UFRGS, Porto Alegre, RS, Brasil.

Pittman, F. S. (1987). Turning points: Treating families in transition and crisis. New York: W. W. Norton \& Company.

Sardinha, A. Falcone, E. M. O., \& Ferreira, M. C. (2009). As relações entre a satisfação conjugal e as habilidades sociais percebidas no cônjuge. Psicologia: Teoria e Pesquisa, 25(3), 395-402.

Schwengber, D., Prado, L. C., \& Piccinini, C. A. (2009). O impacto de uma psicoterapia breve pais-bebê para as representações acerca da maternidade no contexto da depressão. Psico (PUCRS. Impresso), 40, 382-391.

Silva, M. R., \& Piccinini, C. A. (2009). Paternidade no contexto da depressão pós-parto materna: revisando a literatura. Estudos de Psicologia (UFRN), 14, 05-12 .

Snyder, D. K., Cozzi, J. J., \& Mangrum, L. F. (2002) Conceptual issues in assessing couples and families. In H. A. Liddle, D. A. Santisteban, R. F. Levant, \& J. H. Bray (Eds), Family Psychology: Science-based interventions (pp. 69-87). Washington: APA.

Stern, D. (1997). A constelação da maternidade: O panorama da psicoterapia pais/bebê. Porto Alegre: Artes Médicas. 
Stratton, P. (1988). Spirals and circles: Potential contributions of developmental psychology to family therapy. Journal of Family Therapy, 10, 207-231.

Teti, D. M., \& Gelfand, D. M. (1991). Behavioral competence among mothers of infants in the first year: The mediational role of maternal self-efficacy. Child Development, 62, 918-929.

Tudge, J., \& Frizzo, G. F. (2002). Classificação baseada em Hollingshead do nível socioeconômico das famílias do Estudo Longitudinal de Porto Alegre: da Gestação à Escola. Unpublished manuscript. Curso de Pós-graduação em Psicologia do Desenvolvimento, Universidade Federal do Rio Grande do Sul. Porto Alegre, RS.

Walsh, F. (2002). Casais saudáveis e casais disfuncionais: qual a diferença? In M. Andolfi (Ed.), A crise do casal - uma perspectiva sistêmico-relacional (pp. 13-28). Porto Alegre: Artmed.

Walsh, F. (2006). Strengthening family resilience. New York: The Guilford Press.

Watzlawick, P., Beavin, J. H., \& Jackson, D. D. (1975). A pragmática da comunicação humana. São Paulo: Cultrix.

Winnicott, D. (1978). Preocupação materna primária. In Textos selecionados: Da pediatria à psicanálise (pp. 491-498). Rio de Janeiro: Francisco Alves. 